\title{
The Electron Transport System of Kappa Particles from Paramecium aurelia Stock 51
}

\author{
By C. KUNG* \\ Department of Biology, University of Pennsylvania, \\ Philadelphia, Pennsylvania I9Io4, U.S.A.
}

(Accepted for publication 25 February 1970)

\begin{abstract}
SUMMARY
$\mathrm{NADH}$ oxidase activity demonstrated spectrophotometrically in kappa of Paramecium aurelia stock 5I, was inhibited by $\mathrm{KCN}$, antimycin $\mathrm{A}$ and HOQNO. Using a split beam spectrophotometer we obtained low temperature reduced minus oxidized spectra of whole paramecia and of the mitochondrial fraction of paramecia. Two absorption maxima at 588 and $556 \mathrm{~nm}$. were revealed in addition to the peaks of the known $a$ and $c$ cytochromes. From the reduced minus oxidized difference spectrum, the carbon monoxide difference spectrum and other studies, we concluded that kappa has a cytochrome system very different from that of its host but very much like that of bacteria in the families of Brucellaceae and Enterobacteriaceae. The slight contamination in the preparations could not be responsible for the spectra obtained. These findings strongly support the recent belief that kappas and other symbionts in $P$. aurelia are procaryotic in nature and origin.
\end{abstract}

\section{INTRODUCTION}

Purified kappa particles from 'killer' stock 5I of Paramecium aurelia respire aerobically and have the activities of the enzymes of the catabolic pathways (Kung, 1968, 1970). A study of the electron transport system of these particles is reported here. Since most procaryotes have cytochrome systems quite different from the 'typical' cytochrome system of yeast and mammalian mitochondria (Smith, I96I), the present study is very helpful in testing the recent belief that kappas and their 'relatives' are bacterial in nature and origin.

\section{METHODS}

Sensitive (kappa-free) and killer (kappa-bearing) Paramecium aurelia of stock 5I, syngen 4 were cultured in buffered Scotch grass infusion pre-inoculated with Klebsiella aerogenes. Bacillus subtilis was used in two cultures of killers used in obtaining the difference spectra of kappa. Kappa particles were purified using a column of epichlorohydrin triethanolamine cellulose (ECTEOLA) (Mueller, 1963). The kappa preparation was frozen and thawed three times for the study of NADH oxidase activity. Methods of culturing paramecia, and of purifying and counting kappas have been described in detail in Kung, 1968.

NADH oxidase activity was measured by following the decrease in optical density with time at $340 \mathrm{~nm}$. at room temperature using a Beckman DU monochromator with a Gilford model 2000 multiple sample absorbance recorder attachment. Reactions were carried out in a phosphate buffer ( $0.1 \mathrm{M}, \mathrm{pH} 7)$, in a final volume of $2 \mathrm{ml}$. After

* Present address: Zoology Department, Indiana University, Bloomington, Indiana 4740I, U.S.A. 
the addition of pre-counted cell-free kappas, obtained by freezing and thawing three times, the reaction was started with $\mathrm{NADH}$ at a final concentration of $2.05 \times \mathrm{IO}^{-4} \mathrm{M}$. The inhibitors used were $\mathrm{KCN}$, antimycin $\mathrm{A}$ and 2-heptyl-4-hydroxyquinoline-Noxide (HOQNO) supplied by Sigma Chemical Company. Antimycin A and HOQNO were dissolved in ethanol, and control runs with ethanol were made for the assays of these inhibitors.

A split beam spectrophotometer (Chance, 1954) was used in obtaining the difference absorption spectra. For study at the temperature of liquid nitrogen, Estabrook's method with an unsilvered Dewar flask (Estabrook, 1956) was used. The samples were frozen in the low temperature absorption cells with 2 or $3 \mathrm{~mm}$. optical paths designed by Bonner (1961).

To obtain the spectra of paramecia, $2 \mathrm{ml}$. packed sensitive animals of stock $5 \mathrm{I}$ containing no kappa were diluted with $7 \mathrm{ml}$. of $0.0 \mathrm{I}$ M-phosphate buffer, $\mathrm{pH} 6 \cdot 8$. The thick suspension of paramecia was homogenized with a cream homogenizer before use. The mitochondrial fractions of the sensitive paramecia were obtained by conventional methods of differential centrifugation at $500 \mathrm{~g}$ and $5000 \mathrm{~g}$ using a raffinose medium (Preer \& Preer, 1959) and 0.25M-sucrose. Both the purified kappa preparations and the control bacterial fractions were used directly in obtaining the spectra.

Control bacterial mixtures, which simulated qualitatively and exaggerated quantitatively the contaminants in the kappa preparations, were collected by centrifugation ( $14,000 \mathrm{~g}, \mathrm{I} 5 \mathrm{~min}$.) from the culture fluid in which the stock 5I killer paramecia were collected.

\section{RESULTS}

NADH oxidase activity. NADH oxidase activity of cell-free kappa in $0 \cdot 1 \mathrm{M}$-phosphate buffer, $\mathrm{pH} 7$, at room temperature was measured to be $10 \cdot 6 \pm \mathrm{I} \cdot \mathrm{I} \times \mathrm{IO}^{-9} \mathrm{~mole} / \mathrm{min} . / \mathrm{mg}$. dry weight (mean \pm standard error). Antimycin $\mathrm{A}, \mathrm{HOQNO}$ and $\mathrm{KCN}$ were found to inhibit this NADH oxidase activity effectively. Typical experiments showed that $10^{-3} \mathrm{M}-\mathrm{KCN}$ inhibited 70.6 and $71 \cdot 7 \%$ of the NADH oxidase activity: $9.2 \times 10^{-6} \mathrm{M}-$ antimycin $A$ inhibited 72.2 and $73.1 \%$ of the activity, whereas less than $2.1 \times 10^{-5}$ M-HOQNO inhibited 84.9 and $86.5 \%$. Preliminary study showed no cytochrome $c$ oxidase activity (direct oxidation of reduced cytochrome $c$ from horse heart) in either cell-free kappa preparation or the homogenate of the sensitive paramecia.

Difference of spectra of homogenate from whole cell and the mitochondrial fractions of Paramecium. The enzymatically and chemically (dithionite) reduced minus oxidized difference spectra of the homogenate of paramecia were the same. One of these spectra is shown in Fig. I, which was obtained at the temperature of liquid nitrogen. Peaks in the region at 609 and $550 \mathrm{~nm}$. and a broad shoulder at $555 \mathrm{~nm}$., as well as troughs at 579 and $535 \mathrm{~nm}$., were seen. Considering the difference in methods, our result was in good agreement with the spectroscopic observations of Sato \& Tamiya (1937) on Paramecium caudatum. Absorption peaks at 608 and 55I $\mathrm{nm}$. occupied the position of the typical cytochromes $a$ and $c$ and were assigned to these cytochromes by Sato and Tamiya.

A large amount of haemoglobin exists in paramecia. The wide shoulder at $555 \mathrm{~nm}$. and the troughs at 579 and $535 \mathrm{~nm}$. in Fig. I coincide with the absorption maxima of haemoglobin and oxyhaemoglobin respectively (Smith, George \& Preer, 1962). This raises the question of whether other cytochromes might also be present but concealed 
in the spectrum of whole cell homogenate. Since haemoglobin has not been found in mitochondria where the cytochromes are located, we studied the mitochondrial fractions of these sensitive animals in order to test this possibility. The fraction had only a low endogenous respiratory rate which could be increased slightly by substrate but upon which neither ADP nor NADH had any obvious effect. Microscopic observation

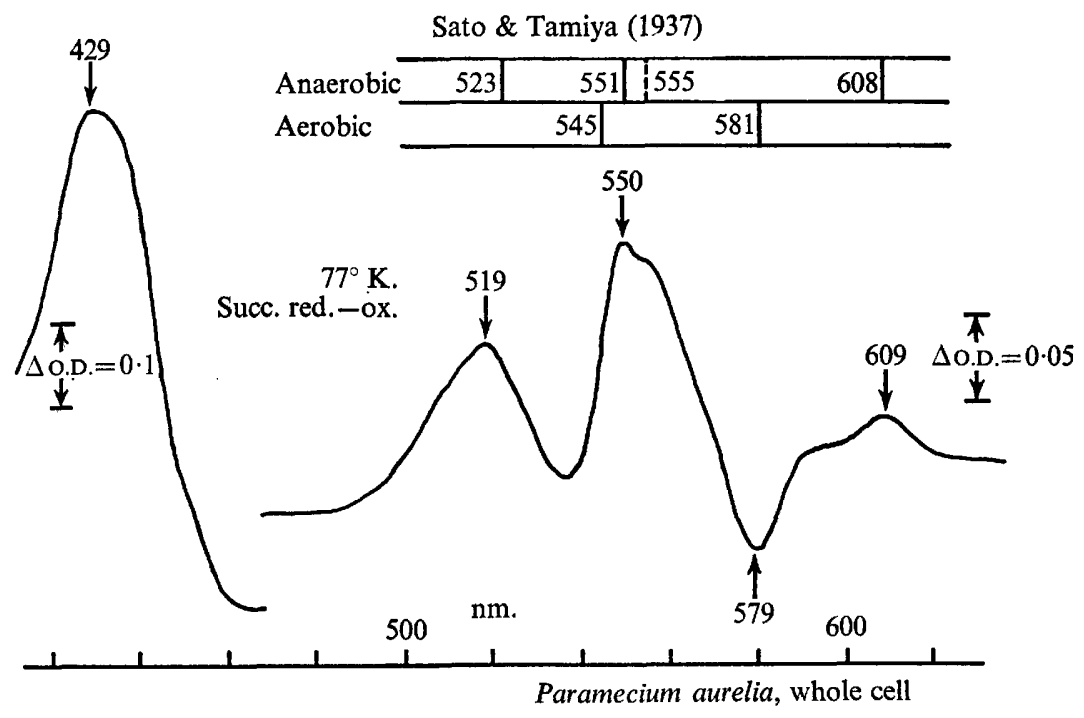

Fig. I. Succinate reduced minus oxidized difference spectrum of Paramecium aurelia, stock $5 \mathrm{I}$, sensitive, at the temperature of liquid nitrogen. The spectroscopic observation of Sato \& Tamiya (1937) is given here for comparison.

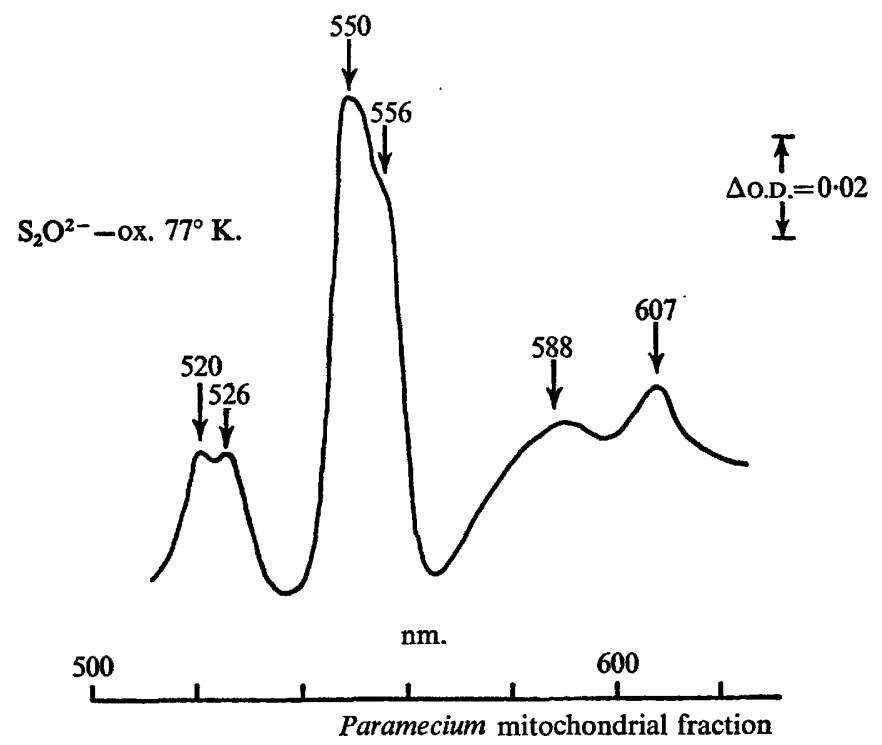

Fig. 2. Dithionite reduced minus oxidized difference spectrum of paramecium mitochondrial fraction at the temperature of liquid nitrogen. 
showed that the mitochondrial fractions contained also trichocysts, cilia and some bacteria (see below and Fig. 4 for the discussion of bacterial contamination). These fractions gave consistent spectra, one of which is given in Fig. 2. The low temperature reduced minus oxidized difference spectra of this type resemble that of the whole animal in their peaks at 550 and $607 \mathrm{~nm}$. The absence of haemoglobin is noted by the loss of the broad shoulder near $555 \mathrm{~nm}$. and the trough at $579 \mathrm{~nm}$. A new shoulder at $556 \mathrm{~nm}$. is found to slope steeply toward a trough at $565 \mathrm{~nm}$. Another small peak is also revealed at $588 \mathrm{~nm}$. A $30,000 \mathrm{~g}$ supernatant of the mitochondrial fraction treated with cetyltrimethyl ammonium bromide (CTAB) (Obayashi et al. 1966) gives an $\alpha$ peak at $548 \mathrm{~nm}$. in low temperature absolute spectrum which is not accompanied by any shoulder (Kung, 1968).

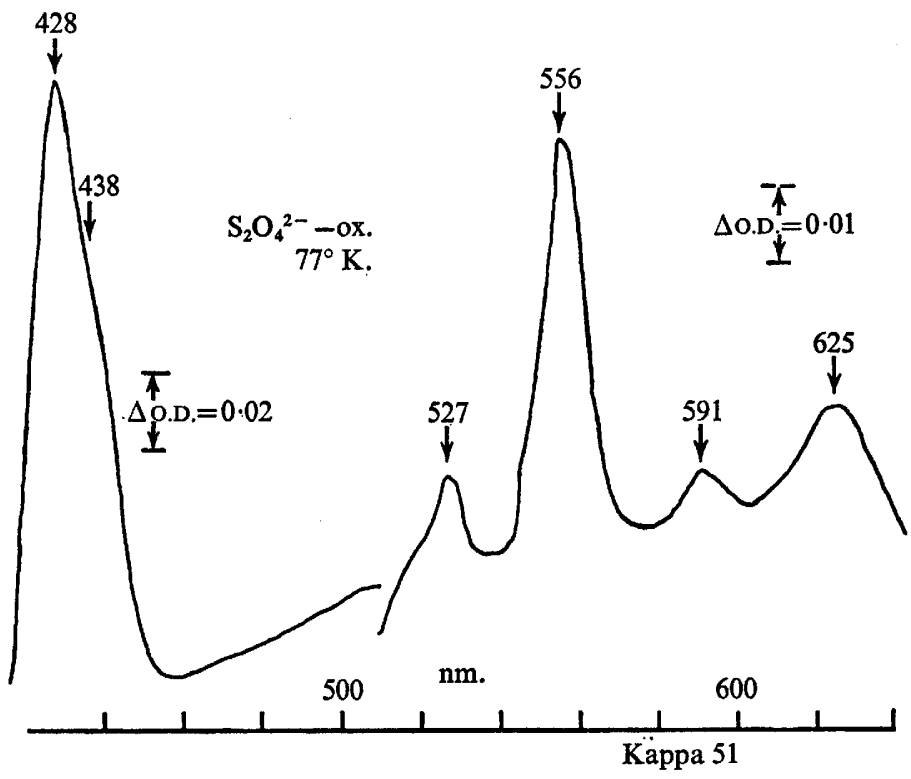

Fig. 3. Dithionite reduced minus oxidized difference spectrum of kappa $5 \mathbf{I}$ at the temperature of liquid nitrogen.

Reduced minus oxidized difference spectra of kappa and control bacteria. In $0.01 \mathrm{M}-$ phosphate buffer, $\mathrm{pH} 6.8$, purified kappas in the order of ${ }^{10} 0^{10} / \mathrm{ml}$. gave consistent spectra. Fig. 3 is one of the spectra obtained from nine kappa preparations of different concentrations reduced in various ways. This dithionite reduced minus oxidized difference spectrum of purified kappa at the temperature of liquid nitrogen is very different from that of whole paramecia (Fig. I) and that of the paramecium mitochondria (Fig. 2). There are two $\alpha$ peaks at 625 and 59I nm. in the $a$ region but only one sharp peak at $556 \mathrm{~nm}$. in the region usually occupied by $b$-or $c$-type cytochromes in the classical systems, similar to the situation in many coliform bacteria (Smith, 196I).

The preparations of kappa came from killer paramecia grown in killer culture started on a food source of either Klebsiella aerogenes or Bacillus subtilis. Besides the species inoculated, however, many other airborne micro-organisms had invaded the cultures before the killers were harvested. These bacteria are apparently the major 
source of contamination. As was described before (Kung, 1968, 1970), the purified kappa preparations were slightly contaminated (from 3000:I up to 300:I in kappa:bacteria ratio) and the above spectrum of kappa is much like the spectra of bacteria in the families of Brucellaceae and Enterobacteriaceae. Critical examination of the possible bacterial contribution to these spectra was made.

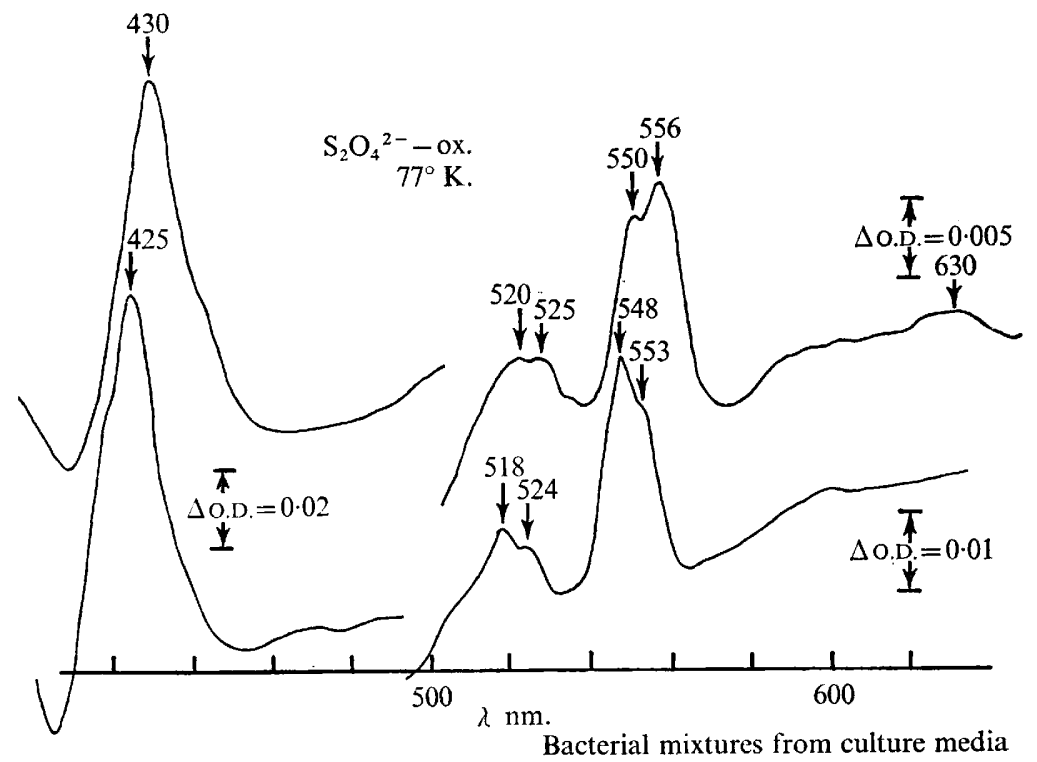

Fig. 4. Dithionite reduced minus oxidized difference spectra of bacterial mixtures collected from killer cultures. These spectra were obtained at the temperature of liquid nitrogen.

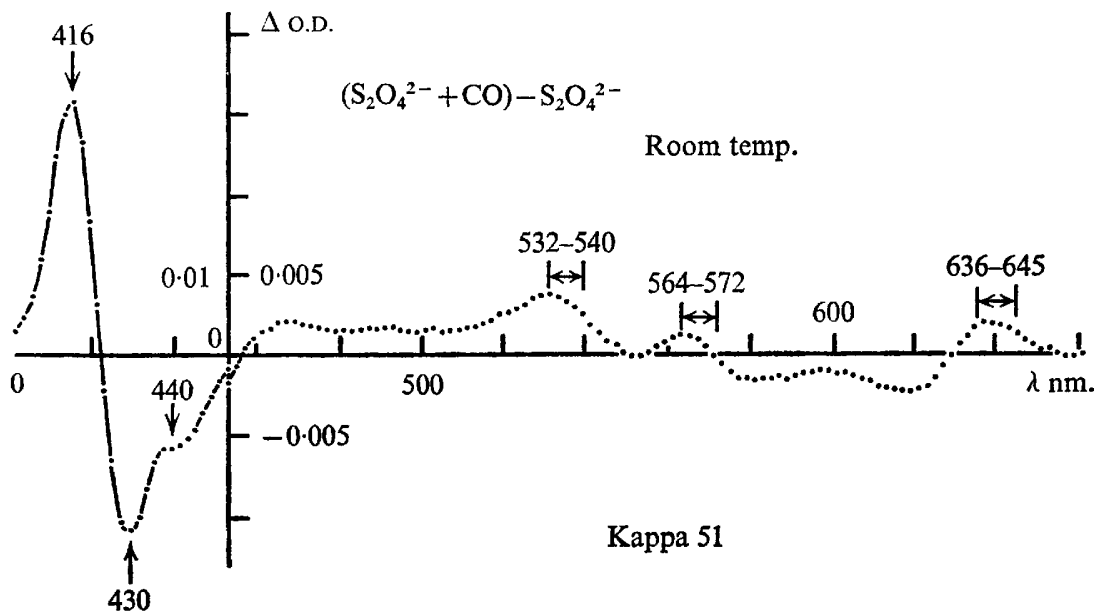

Fig. 5. Carbon monoxide treated minus reduced difference spectrum of kappa $5 \mathrm{I}$ at room temperature.

Bacteria in the order of $10^{7}$ to $10^{8} / \mathrm{ml}$. from the cultures of killers whose kappas were used in spectral studies gave only the baseline in spectral analysis. Spectra of these bacterial mixtures in the order of ${ }_{10} 0^{10} / \mathrm{ml}$. are shown in Fig. 4. Not only did these 
spectra differ from that of kappa, but they also differed from each other and from the spectra of any single bacterial species reported. Thus neither were the contaminants quantitatively sufficient to produce the spectrum of kappa, nor were their spectral characteristics qualitatively similar to those of kappa.

$C O$ difference spectra of kappa. Figure 5 is one of the carbon monoxide difference spectra of purified kappa preparation, obtained at room temperature and corrected for the baseline. Spectra of this kind showed a peak at 4I5 to $4 \mathrm{I} 7 \mathrm{~nm}$., a trough around $430 \mathrm{~nm}$. and plateau near $440 \mathrm{~nm}$. in the $\gamma$ region. The peaks in the $\alpha$ and $\beta$ regions were not prominent even with the magnification produced by low temperature. The two $\alpha$ peaks at room temperature ranged from 636 to $645 \mathrm{~nm}$. and 564 to $572 \mathrm{~nm}$. in several studies. The peak at $4 \mathrm{I} 5$ to $4 \mathrm{I} 7 \mathrm{~nm}$. was thought to belong to cytochrome $o$, a cytochrome peculiar to procaryotes. That this peak was produced by an active cytochrome oxidase is confirmed by the photochemical action spectrum in a preliminary study using the technique of Hyde (1967) (Kung, I968).

\section{DISCUSSION}

The cytochrome systems of paramecium have not been extensively studied before. Unmasking the haemoglobin showed the existence of more cytochromes than just $a$ and $c$, as reported by Sato \& Tamiya (1937). While cytochrome oxidase activity was indirectly demonstrated in paramecia (Simonson \& van Wagtendonk, I952; Boell, I945; Preer \& Preer, 1959), none of the methods used involved direct reduction of cytochrome $c$. From our findings we conclude that there are oxidases in kappa but they do not oxidize the 'typical' cytochrome $c$ of mammals. The hump revealed at $588 \mathrm{~nm}$. might correspond to the 580 to $590 \mathrm{~nm}$. diffuse band spectroscopically observed by Ryley (1952) in Tetrahymena pyriformis which he considered to be the band of cytochrome $a_{1}$ or oxyhaemogoblin. Since we observed this $588 \mathrm{~nm}$. peak consistently in the difference spectra of the mitochondrial preparations from Paramecium aurelia, it is not likely that it could be the absorption peak of oxyhaemoglobin or bacterial contamination, which varied from time to time (Fig. 4). Thus we tentatively assign this peak to cytochrome $a_{1}$ of paramecium. The identity of the $556 \mathrm{~nm}$. shoulder is uncertain, although this spectral position at low temperature speaks against the possibility of many $c$-type cytochromes. When a $c$-type cytochrome is extracted by CTAB, this shoulder is not seen to accompany it. Tests on the stability to heat and acidity changes such as solubility test upon acetone- $\mathrm{HCl}$ treatment will help to ascertain the nature of this cytochrome.

The similarity between the difference spectrum of kappa and that of Klebsiella aerogenes and other coliform bacteria (Smith, 196I; Kung, 1968) is of great help in identifying the cytochromes in kappa particles. The two low peaks at the $a$ regions, from $62 \mathrm{I}$ to $626 \mathrm{~nm}$. and from 585 to $592 \mathrm{~nm}$. in the reduced minus oxidized spectra of kappa, agree with the $\alpha$ bands of $a_{2}$ and $a_{1}$ respectively in these bacteria. The peaks in the $\mathrm{CO}$ difference spectrum (Fig. 5) also support this assignment. The existence of cytochrome $o$ is clearly demonstrated by the CO difference spectrum, for the $\gamma$ peak at $4 \mathrm{I} 6 \mathrm{~nm}$. is unique for CO-compound of this cytochrome oxidase. Our preliminary study of the $\mathrm{CO}$ action spectrum also revealed the same peak. In the reduced minus oxidized difference spectrum of kappa (Fig. 3) the region for the $\alpha$ bands of $b$-and $c$-type cytochromes is occupied by a single sharp peak, the position of which agrees 
with the peak of cytochrome $b_{1}$ in coliform bacteria (Smith, I96I; Kung, I968). HOQNO difference spectra (see Kung, 1968) also bear this out.

The KCN, CO and HOQNO inhibition of the aerobic respiration of kappa particles (Kung, 1970) as well as the presence and inhibitory characteristics of the NADH oxidase indicate the existence of an electron transport system in kappa. Perhaps the most significant finding is that the cytochrome system of kappa particles as revealed in this study is completely different from that of their hosts, the paramecia. The kappa system is strikingly procaryotic in character and is almost identical with the system of bacteria in the families of Brucellaceae and Enterobacteriaceae, but differs from those in Azotobacteriaceae, Lactobacteriaceae, Pseudomonadaceae, Bacillaceae and Micrococcaceae. Control experiments with bacteria had shown that the slight amount of contamination in the kappa preparations was not significant. That kappa has spectra like those of Klebsiella aerogenes is purely coincidental. Like Klebsiella (Aerobactor) aerogenes, Escherichia coli and Proteus vulgaris (Smith, I954a, b, I96I) kappa seems to have a similar system of cytochrome $a_{1}, a_{2}, b_{1}$ and $o$. Having more than one, in this case three, cytochrome oxidases is not the case in a 'typical' eucaryotic system. Cytochrome $o$, in particular, is strictly an oxidase of bacteria and blue-green algae (Smith, I96I; Webster \& Hackett, I966). None of the absorption peaks of the 'typical' cytochrome system of yeast and mammalian mitochondria is seen in the spectra of kappa preparations. In fact, a trough appears at $340 \mathrm{~nm}$. in the carbon monoxide difference spectrum of kappa where the major peak of cytochrome $a_{3}-\mathrm{CO}$ complex should be.

These findings justify the belief that kappas and their 'relatives' are bacterial in origin and have retained a large number of procaryotic characteristics.

I thank Dr Walter A. Bonner, Jun., and Dr John Biggins for the use of their laboratories and for their advice. Some of the spectra in the earlier part of the study were obtained by Dr Bonner. I am also grateful to Dr John R. Preer, Jun., for reviewing this manuscript.

This work was supported by grants from the National Science Foundation and Phi Beta Psi to Dr John R. Preer, Jun.

\section{REFERENCES}

Boell, E. J. (1945). Respiratory enzymes in Paramecium. I. Cytochrome oxidase. Proceedings of the National Academy of Sciences of the United States of America 31, 396-402.

BonNer, W. D. Jun. (196I). The cytochromes of plant tissues. In Haematin Enzymes. Edited by J. E. Falk, R. Lemberg \& R. K. Morton. New York: Pergamon Press.

ChANCE, B. (1954). Spectrophotometry of intracellular respiratory pigments. Science, New York I20, 767-775.

EstabrooK, R. W. (1956). The low temperature spectra of haemoproteins. I. Apparatus and its application to a study cytochrome $c$. Journal of Biological Chemistry 223, 781-784.

HydE, T. A. (1967). The Design and Use of a New Instrument for the Investigation of Photochemical Dissociation of Carbon Monoxide Inhibited Respiration. Dissertation, University of Pennsylvania.

Kung, C. (1968). Oxidative Metabolism of Kappa Particles from Paramecium aurelia, stock 5I in relation to their Nature and Origin. Dissertation, University of Pennsylvania.

KUNG, C. (1970). Aerobic respiration of kappa particles from Paramecium aurelia, stock 51. Journal of Protozoology (In the Press).

MUeller, J. A. (I963). Separation of kappa particles with infective activity from those with killing activity and identification of the infective particles in Paramecium aurelia. Experimental Cell Research 30, 492-508. 
Obayashi, A., YorifuI, H., Yamagata, T., IJICHI, T. \& KANIE, M. (I966). Respiration in organic acid-forming molds. Part I. Purification of cytochrome $c$. coenzyme $Q_{g}$ and L-lactic dehydrogenase from lactate-forming Rhizopus oryzae. Agricultural and Biological Chemistry 30, 717-724.

PreER, J. R. JUN. \& Preer, L. B. (1959). Gel diffusion studies on the antigens of isolated cellular components of Paramecium. Journal of Protozoology 6, 88-100.

RYLEY, J. F. (1952). Studies on the metabolism of the protozoa. 3. Metabolism of the ciliate, Tetrahymena pyriformis (Glaucoma pyriformis). Biochemical Journal 52, 483-492.

Sato, T. \& TamiYa, H. (1937). Über die Atmungsfarbstoffe von Paramecium. Cytologia, Tokyo, Fujii jub. II33-II38.

Simonson, D. H. \& VAN Wagtendonk, W. J. (1952). Respiratory studies on Paramecium aurelia variety 4, killers and sensitives. Biochemica et Biophysica Acta 9, 515-527.

Sмrth, L. (1954a). Bacterial cytochromes. Bacteriological Reviews 18, 106-130.

SMrTH, L. (1954b). Bacterial cytochromes, difference spectra. Archives of Biochemistry and Biophysics 50, 299-314.

SmITH, L. (196I). Cytochrome systems in aerobic electron transport. In The Bacteria, vol. II. Edited by I. C. Gunsalus \& R. Y. Stanier. New York: Academic Press.

Smith, M. H., George, P. \& Preer, J. R. JUN. (1962). Preliminary observation on isolated paramecium haemoglobin. Archives of Biochemistry and Biophysics 99, 313-318.

WeBsTER, D. A. \& HACKETT, D. P. (1966). Respiratory chain of colourless algae. II. Cyanophyta Plant Physiology 41, 599-605. 